\title{
EXPERIMENT OF HYSTERETIC BEHAVIOR AND STABILITY PERFORMANCE OF BUCKLING-RESTRAINED BRACED COMPOSITE FRAME
}

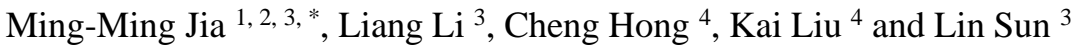 \\ ${ }^{1}$ Institute of Engineering Mechanics, China Earthquake Administration, Harbin 150080, P. R. China; \\ ${ }^{2}$ Key Laboratory of Earthquake Engineering and Engineering Vibration of China Earthquake Administration, Harbin 150080, P. R. China \\ ${ }^{3}$ School of Civil Engineering, Harbin Institute of Technology, Harbin 150090, P. R. China \\ ${ }^{4}$ School of Civil Engineering and Architecture, Nanchang Institute of Technology, Nanchang 330099, P. R. China \\ (Corresponding author: E-mail: jiamingming@hit.edu.cn)
}

\section{A B S T R A C T}

One large-scale 2-story 1-bay buckling-restrained braced (BRBed) concrete-filled steel tube column composite frame (BRBCF) was tested, and the quasi-static cyclic test of the outer composite frame (CF) of BRBCF for comparison. The lateral stiffness, ultimate load bearing capacity and energy dissipation capability of the composite frame were significantly improved when installed with the BRBs. BRBCF exhibited good hysteretic behaviour and sustained story drifts of nearly $2 \%$ with large BRB maximum ductility demands, which was a double lateral-resistance structure system with high efficiency. The bolt splices connections of BRBs with CF frame played the intended function perfectly, but the test also indicated that the large flexural demand occurred on the typical beam-column-brace connection that caused the failure of $\mathrm{BRB}$ connection segments. In the test, in addition to the axial force, the buckling-restrained braces in the BRBCF were also affected by the bending moment, which led to the out-of-plane buckling of BRB bolt splices connection and significant decrease of bearing capacity and stiffness of the frame system. According to the failure modes of BRBCF, the reasons of joint failure were analyzed, and the design suggestions of improving the stability performance of BRB unrestrained connection segments were proposed.
ART I CLE H I S T O RY

$\begin{array}{ll}\text { Received: } & \text { 4 June } 2020 \\ \text { Revised: } & \text { 6 February } 2021 \\ \text { Accepted: } & \text { 6 February } 2021\end{array}$

\section{K E Y W O R D S}

Buckling-restrained brace;

Hysteretic behaviour;

Stability performance

Maximum ductility;

Energy dissipation;

Composite frame

\section{Introduction}

The Buckling restrained brace (BRB) resists the axial force with a full tension or compression yielding capacity without the local or global flexural buckling failure. The BRB exhibits nearly identical properties in tension and compression, which has the ability to undergo numerous cycles of inelastic deformations without strength and stiffness degradation or fracture. As a part of buckling- restrained braced frames (BRBFs), BRBs are usually installed concentrically in the frames, and provide evidently good seismic performance as braced frame systems. The superior performance of BRBFs results from the robust cyclic behavior exhibited by BRBs with significant stiffness, energy dissipation capacity and ductility. The frames installed with BRBs have been used widely in building constructions in the real world, such as U.S. Salt Lake City state building, Japan Toyota Stadium and China Tianjin 101 building.

Aiken et al. [1] conducted three cyclic tests on a 0.7 -scale one-bay one-story BRBF. The columns exhibited flexural and shear yielding, and the gusset plates, beam-column-brace connections, column, beam initiate cracks. Iwata et al [2-3] evaluated the performance of a ten-story dual system combining MRFs and BRBFs through time-history analyses. The response of BRB separated from the global system during time-history analyses was evaluated on the basis of the $\mathrm{BRB}$ performance criteria with respect to the maximum and cumulative ductility capacities. This fracture led to large torsional rotations of the beam and out-ofplane deformation of the BRB. Two big-scale BRBFs tested by Tsai et al. [4], which developed distortion in BRB gussets at story of $0.01 \mathrm{rad}$, and the instability was attributed to the long brace-gusset plate connection Regions. Christopulos [5] tested five full-scale one-bay one-story BRBFs under cyclic displacement histories. The BRB gusset connections were bolted and the connections of beams and columns were via of single-plate shear tabs. BRB failure was typically preceded by yielding and buckling of the gusset plates at the beam-column joints. Roeder et al. [6] tested five full-scale one-story onebay BRBFs. The effects of gusset plate geometry, type of bolted brace-gusset plate connections were investigated, and the variations between test specimens had minimal influence on performance. Four of the five BRBFs failed due to out-of-plane deformation of the BRB at 0.022 to $0.024 \mathrm{rad}$ story drift. Chou and Liou et al. [7, 8] proposed a new BRB that the dual gusset plates sandwiching an inner core to reduce gusset plate size and eliminate the need for splice plates, and the connection stability under compression was enhanced. Use of dual corner gusset plate can eliminate buckling of single-angle gusset plate without free edge. The large-scale shaking table simulation test method was used to perform stability tests on the single-bay and single-story steel frames, and the out-of-plane stability of steel frames under the chevron arrangement of BRBs was studied. When the force of the steel core is less than its yield strength, the BRBs with a flexible section at each end of the steel core will fail due to out-of- plane buckling. Tsuyoshi Hikino et al. [9] proposed a simple stability model that predicted the mechanism of BRBs. In this study of Chuang [10], 581 BRBF design examples were studied, and the effectiveness of the proposed design procedures to meet all design requirements was analyzed. It was found that the most critical limit states for an initial design are joint region buckling, gusset plate buckling, gusset-to-beam and gusset-to-column interface strength. Recommendations on initial selections including the BRB joint size and gusset plate thickness were given. Four BRB end deformation modes for quick determination of end rotational demand were proposed for non-moment BRBF, and key factors affecting BRB end rotation and flexural moments were examined theoretically by parametric analysis by Zhao et al. [11, 12]. Zhao et al. [13] found that the triggering moment induced by rigid-body rotation of BRB ends and the amplified moment resulted from bending and semi-rigid effects of the connections were responsible for premature in-plane buckling of the BRB end connections, and an equivalent rigidity concept was proposed to combine the contributions of both flexural and rotational rigidities of the entire connection. Because the BRBs have a higher ductility coefficient, Jamkhaneh et al. [14] found that the structural response modification coefficients of steel frame with the regular cross convergent BRBs were 44 and $41 \%$ bigger than those of the frame system. The effects of diagonal angles of BRBs on the structural seismic performance characteristics were evaluated by Sadeghi et al. [15]. BRBs can be used to partially replace the diagonal elements and improve the seismic performance of diagrid structures by efficiently accumulating the plastic damages in BRBs.

Although the afore-mentioned studies have been conducted, there are still some problems under research, especially the joint of concrete filled steel tube column, steel beams and buckling-restrained brace is complicated, the failure mode and mechanics properties of which should be studied.

In this paper, the boundary members of the structure are mainly concentrated on concrete-filled steel tubular columns and steel beams, and the energy dissipation capacity, hysteretic behavior, bearing capacity, maximum ductility and failure mode were investigated on BRBCF system. This paper describes the details of the design procedure and the results of the BRBCF using the bolted BRB gusset connection from quasi-static cyclic testing. The failure modes of BRBCF on system-level were researched. The out-of-plane buckling of unrestrained connection segments of buckling-restrained braces were investigated and the effect on structural performance was studied. The behavior and failure mode of the BRBCF joints were fully investigated. The reasons of joint failure were analyzed, some suggestions for improving the connection performance were proposed. Compared with composite frame system, the research indicated that the performance of BRBCF system increased evidently due to the contribution of the BRBs. 


\section{Design and fabrication of test specimens}

BRB's load-carrying core elements is divided into a restrained yielding part, two restrained non-yielding parts and two unrestrained non-yielding parts, as shown in Fig. 1. We welded two steel plates at both ends of the inner core on both sides of the original steel plate, so changed the cross section to crisscross section. The end enlarged section can provide space for connection and extra flexural rigidity for buckling strength. To ensure the first yielding and full development of energy dissipation capacity of the restrained yielding part, the elastic tension and compression strength of unyielding segment were 2.54 times of the ultimate strength of yielding part, because the cross section area of unyielding segment were 3.12 times of yielding part, while the yielding strength of inner core steel is 0.814 times of the ultimate strength. Four stories of plastic film $(0.2 \mathrm{~mm}$ in thickness) were adopted as unbounding material between steel inner core and concrete. We precisely positioned the load-bearing component in the center of the steel tubes, welded a seal plate at one end of the steel tube, and then casted the concrete into a steel tubes, as shown in Fig. 2. After the concrete is cured, another seal plate was welded on the other end of the steel tube.
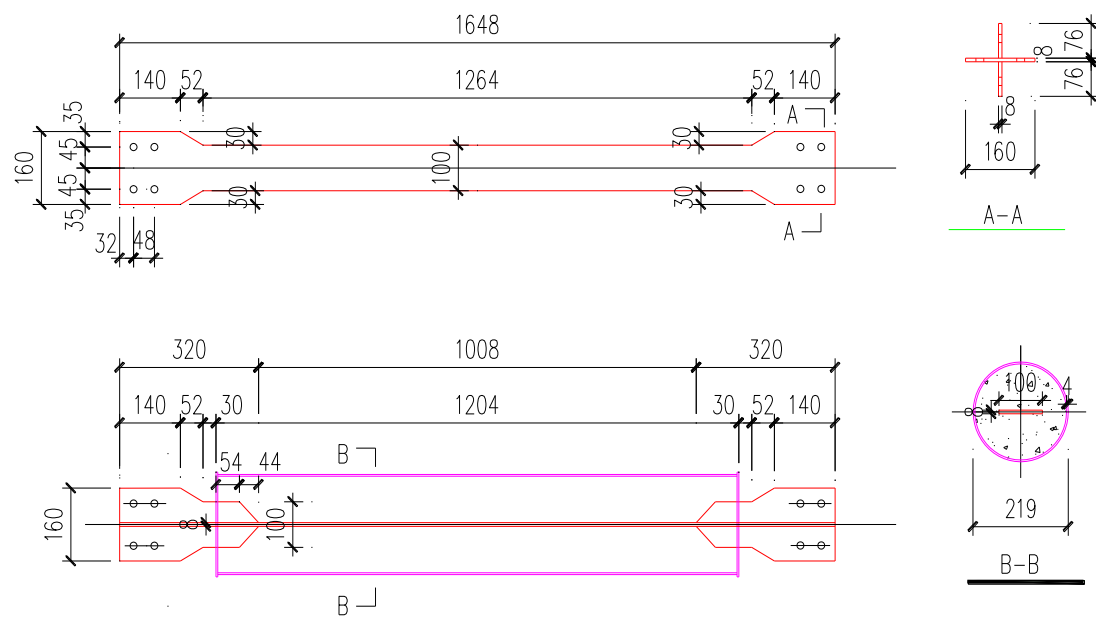

Fig. 1 Dimensions of BRB specimens

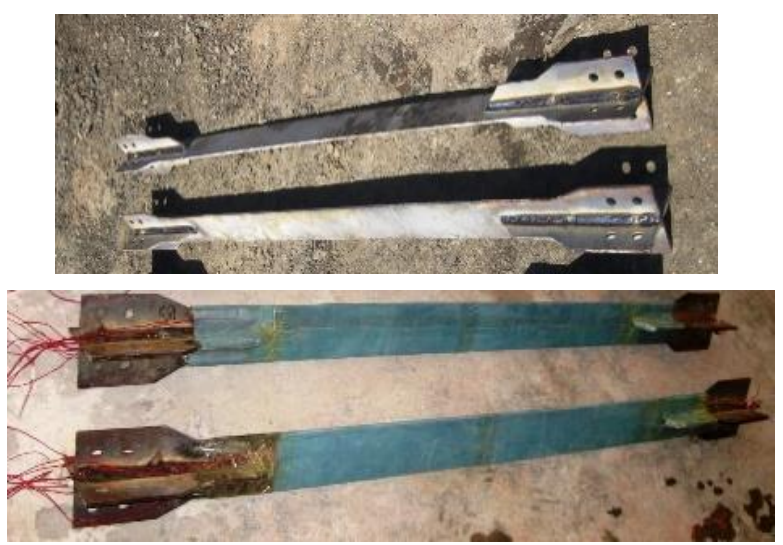

(a) The inner cores of BRBs

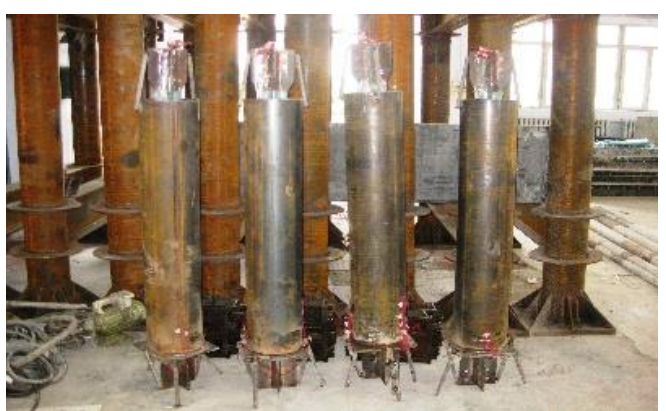

(b) The BRB specimens

Fig. 2 Fabrication process of BRB specimens

The specimen frame consisted of concrete-filled circular hollow section (CHS) steel columns and steel beams, and the composite moment frame was installed with BRBs. In this study, a one-bay, two-and-half- story specimen was designed acting as a lateral load-bearing system. The prototype structure of test specimen was used as the middle two floor sub-assemblies of a building, and the structure was designed with Chinese codes including Chinese code for seismic design of buildings (GB50011-2010) [16], Chinese code for design of steelconcrete composite structure (DL/T5085-1999) [17], Chinese code for design of steel structure (GB50017-2003) [18]. The buckling-restrained braces were designed with checking of global and local stability performance [19]. The 1/2 scaled story height was $1500 \mathrm{~mm}$, and the scaled span length was $2000 \mathrm{~mm}$, as shown in Fig. 3. The dimension of circular steel tubes was $219 \mathrm{~mm} \times 4 \mathrm{~mm}$ (Diameter $x$ steel tube wall thickness). The dimensions of middle beam, top and bottom beams were $H 194 \times 150 \times 6 \times 9(\mathrm{~mm}$, web height $\times$ flange width $\times$ web thickness $\times$ flange thickness), $\mathrm{H} 300 \times 150 \times 6.5 \times 9(\mathrm{~mm}$, web height $\times$ flange width $\times$ web thickness $\times$ flange thickness). The rectangular cross-sectional area of the inner core of BRB was $100 \mathrm{~mm} \times 8 \mathrm{~mm}$ (width $\times$ thickness). The specimen had a half story at the bottom, and the height of it was $600 \mathrm{~mm}$. The construction of half story was used to adapt the position of test specimen to suit the load actuators on the reaction wall. The specimen was connected to the rigid base beam by bolts and stiffeners capable of transmitting plastic moments, and then the rigid base beam was pretensioned to the strong floor according to the uplift check of the specimen during testing. Chinese Q235B steel was adopted with nominal yielding stress of $235 \mathrm{MPa}$, elastic modulus $E_{s}=2.0 \times 10^{5} \mathrm{~N} / \mathrm{mm}^{2}$, poisson ratio $v=0.287$. Test characteristics of steel such as the yielding strength $f_{y}$, ultimate tensile strength $f_{u}$, the ratio $\gamma$ of ultimate tensile strength and the yielding strength, ultimate strain $\varepsilon_{\max }$ are listed in Table 1 . The test compressive stress of filled C30 concrete is $28.92 \mathrm{MPa}$. 

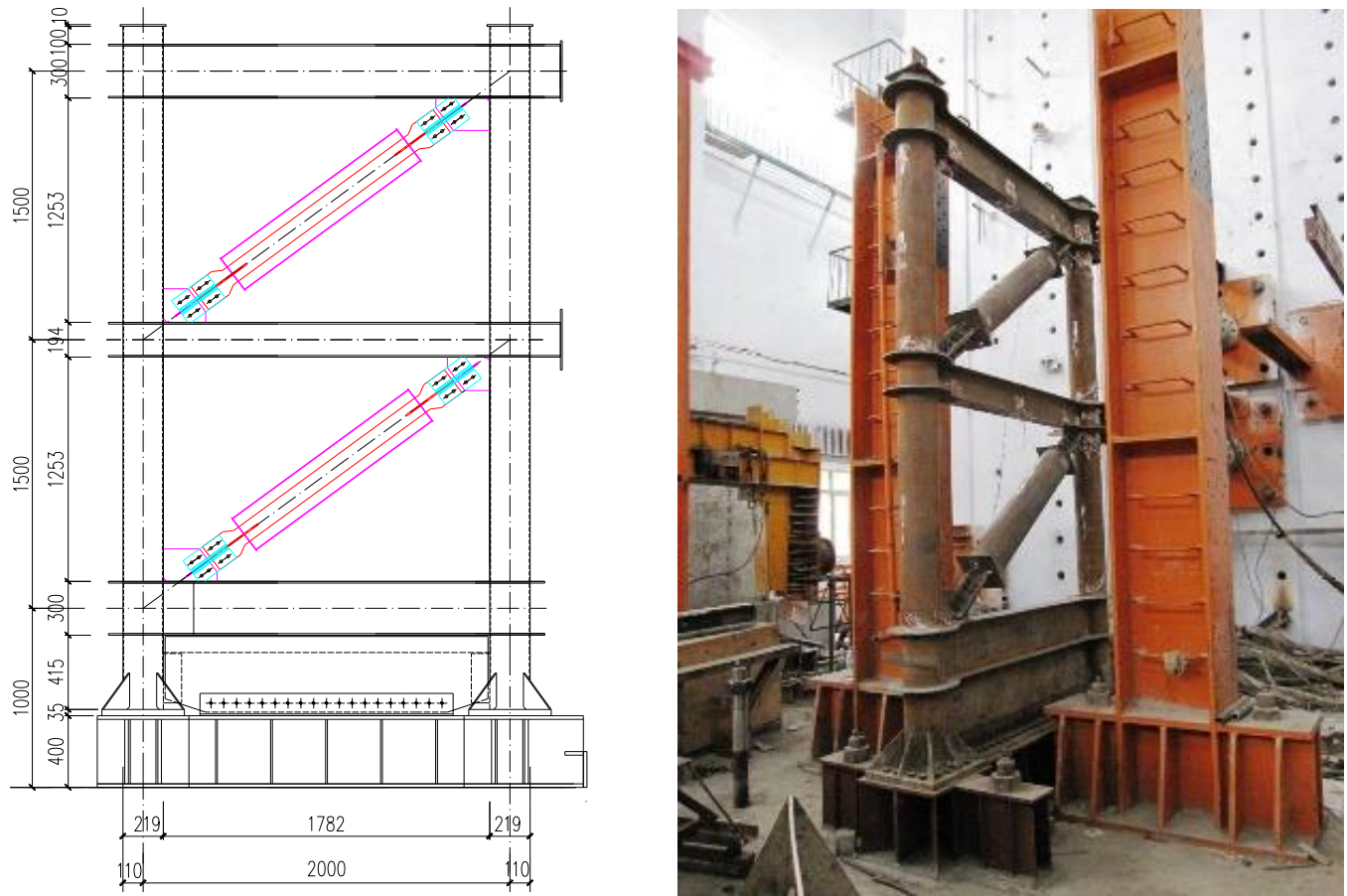

Fig. 3 The BRBCF specimen

Table 1

Characteristics of steel

\begin{tabular}{cccc}
\hline & Stell inner core & Outer circle steel tubes & H steel \\
\hline$f_{y}\left(\mathrm{~N} / \mathrm{mm}^{2}\right)$ & 263 & 298 & 261 \\
$f_{u}\left(\mathrm{~N} / \mathrm{mm}^{2}\right)$ & 379 & 366 & 413 \\
$\gamma$ & 1.44 & 1.23 & 1.58 \\
$\varepsilon_{\max }$ & $25 \%$ & $31.7 \%$ & $26.94 \%$
\end{tabular}

The joints of BRBCF are always in the complicated stress conditions under moment, shear and torsion combination actions. When the ultimate load-bearing capacity of joints were reached, the joints would buckle and fracture. The failure of the joints of BRBCF will result the collapse of structure, and the casualties are unavoidable. So the design and construction of joints are very important for structural performance and personnel safety. The moment connections were adopted in the composite frame, the composite column and steel beam were connected with the enforced loops. The internal diaphragms of enforced loops have are shown in Fig. 4, and the thickness of enforced loops is as same as beam flange thickness, the enforced loops can transfer the stress of beam flanges uniformly to the columns. So the failure of connections can be avoided effectively based on the above joint configuration.

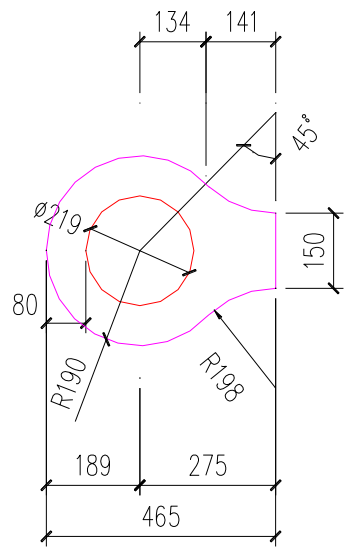

(a) The left side

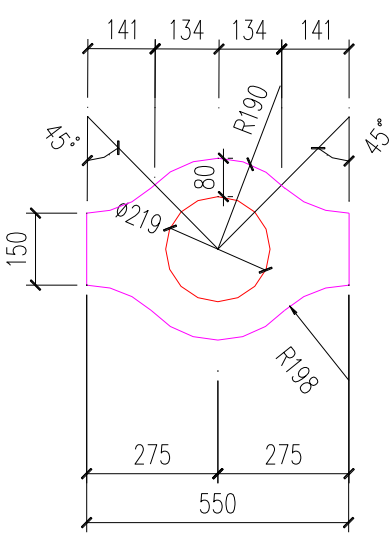

(b) The right side
Fig. 4 The internal diaphragms of the enforced loops
As shown in Fig. 5, one BRB was installed diagonally in one story, and each BRB end gusset connection employed 8 unconstrained splice plates and $16 \mathrm{~mm}$ diameter M16 bolts. Typical BRB gusset plates located at the beamcolumn joints, and the centrelines of column, beam and the BRB intersected at the same point.
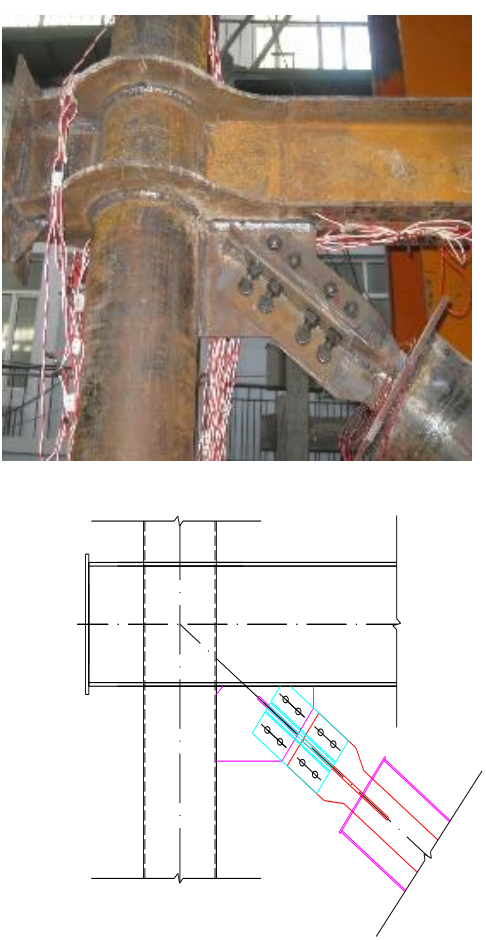

Fig. 5 The details of the frame joint and BRB connection

There are three reaction points and one load point (two column bases and one ground-level link) used as four in-plane attachments for the test planar frame structure, and the experimental setup is shown in Fig. 6. 

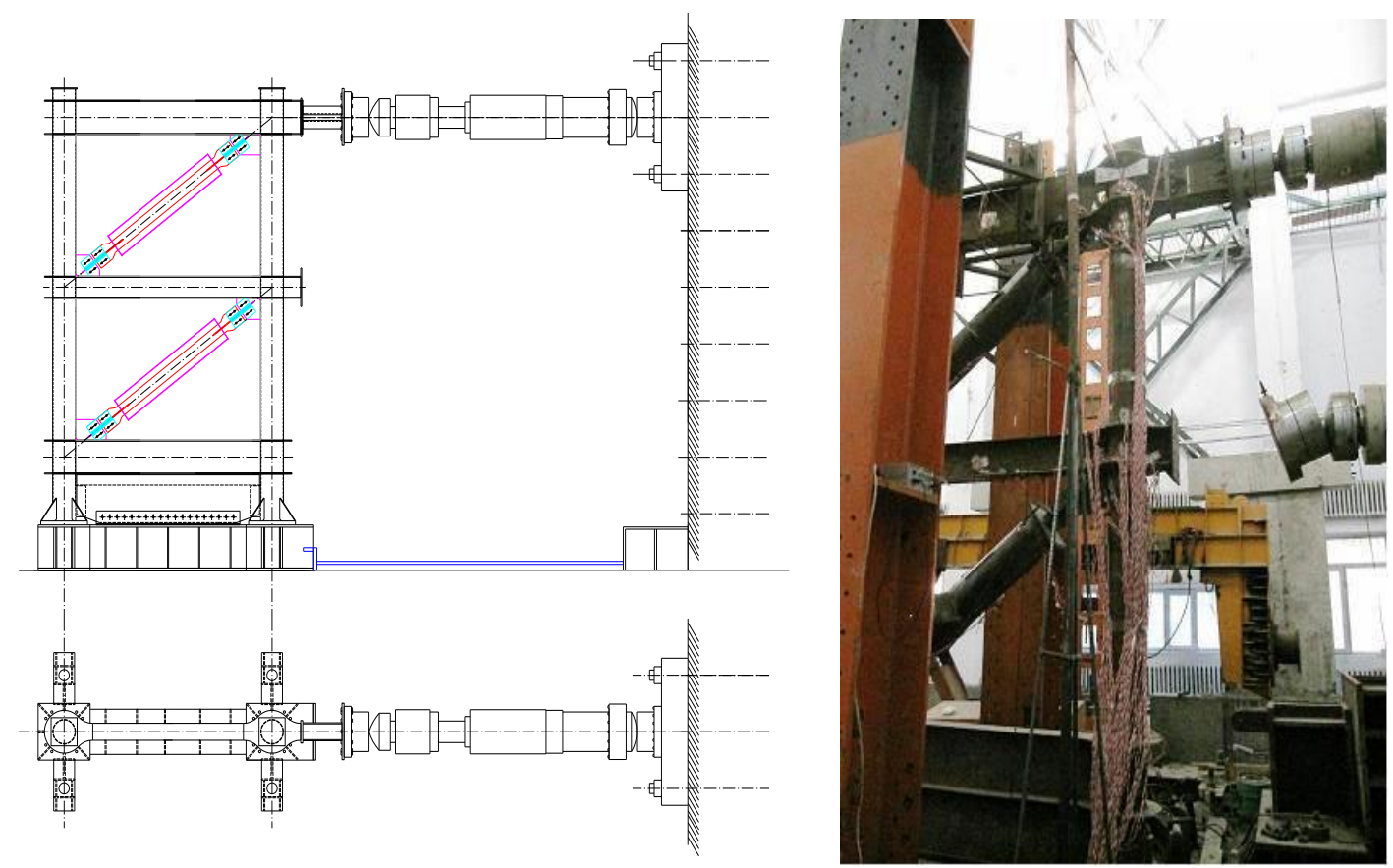

Fig. 6 The experimental setup of BRBCF

The ground-level link was anchored at the reaction wall, and the rigid base beam was fixed on the rigid floor to prevent the overturn of test specimen. One electro-hydraulic servo actuator was attached to the reaction wall, and the electro-hydraulic servo actuator was employed to apply in-plane loading on the specimen at the top story. The actuator with individual loading capacity of $630 \mathrm{kN}$ applied the loads through loading beam to the top beam midpoints of test frame. The applied actuator force was measured by the load cell. The top beam was restrained with dual lateral bracing frames, which were used to avoid outof-plane buckling of the specimen frame, and almost no planar resistance was provided by four rollers.

Strain gauges were stuck on vital positions of beams, columns and the inner core of BRBs. Linear Variable Displacement Transducers (LVDTs) were used to measure the absolute horizontal displacement of each story and the relative displacement between the column base and the strong floor. Through the LVDTs at the top beam we could measure the out-of-plane deformation of the entire frame. The loading scheme in Chinese specification of testing methods for earthquake resistant building (JGJ 101-2015) [15] was adopted. Firstly, the incremental elastic load was $50 \mathrm{kN}$ from $0 \mathrm{kN}$, and each load amplitude was applied as a load cycle. In the plastic range, the increasing frame roof displacements were taken as control quantity, which were integral multiples of $10 \mathrm{~mm}$, and three cycles of the same displacement amplitude were applied for the test frame at each load amplitude.

\section{Experimental phenomena}

As shown in Fig. 7, circle points are used to indicate the yielding locations of components, the yielding sequence numbers are also presented in Fig. 7. The frame remained elastic within the range of lateral load of $200 \mathrm{kN}$. At this stage, the load increased linearly with the increment of story drift. At the lateral load of $250 \mathrm{kN}$, the principal strain indicated that the BRB cores began to yield, while the main frame remained resilient. During the cycles of sequence at approximately $1 / 300$ frame roof drift (10mm roof displacement), due to the yielding of BRBs at 1,2 points, the stiffness of BRBF began to decrease. Note that the BRB was connected to the beam flange. At the top drift of $1 / 150(20 \mathrm{~mm}$ roof displacement), 3, 4 points at the middle beam flange yielded near the beamcolumn-brace connection. At the loading cycles of approximate 1/100 frame roof drift ( $30 \mathrm{~mm}$ roof displacement), 5, 6 points opposite to 3,4 points yielded at the middle beam's flange. When the top story displacement was $40 \mathrm{~mm}$, the 7,8 points of the beam web yielded, and plastic hinges were formed at both ends of the web beam. At the top story drift of $1 / 50$ (about $60 \mathrm{~mm}$ roof displacement), flexural and shear yielding occurred on the columns, 9, 10 points at the column bases of the first story began to yield. The frame action force was resulted from the BRB axial force on the frame, which had an influence on the yielding of the beam-column-brace connection regions. 11, 12 points at the column base and 13,14 points at the column top yielded sequentially, especially close to the enforced loop regions. BRBs and main frame yielded in proper order, and BRBs acted as the structural fuse and yielded before the main frame.

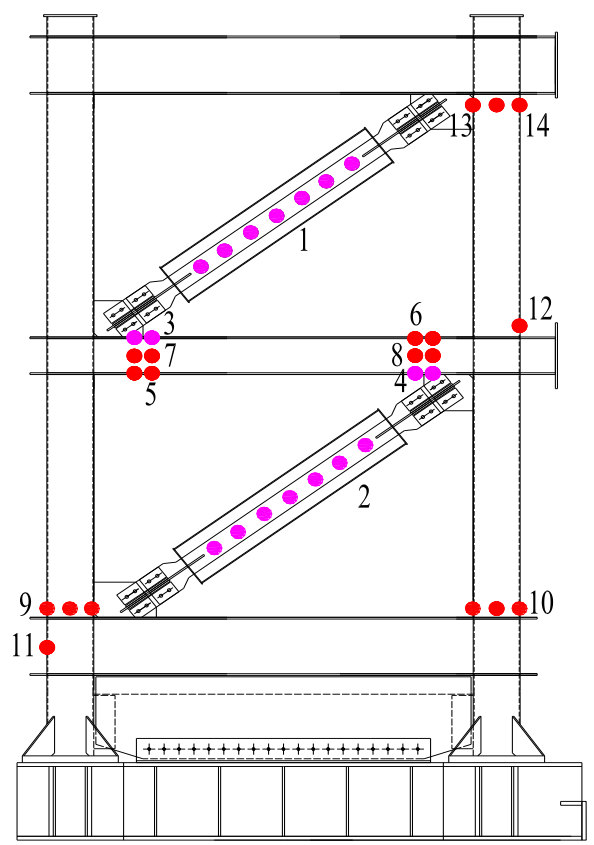

Fig. 7 Yielding locations and sequence

As shown in Fig. 8, the unrestrained connection segments of BRBs buckled at the approximate frame roof displacement of $60 \mathrm{~mm}$, which resulted the large out-of-plane rotational deformation of the unrestrained connection segments of BRBs in two stories, but the rotational direction is opposite. Therefore, the bearing capacity and stiffness of BRBCF are significantly reduced, so the test is completed at this load level.

The BRBCF specimens showed good ductility, and there was evident plastic deformation development on BRBs, beams and columns. The BRBs, acting as fuses, yielded at a fairly low drift of $1 / 300$, and dissipated almost all energy before the frame yielded. The requirement that BRBs should begin to yield at less than $1 \%$ drift was indeed satisfied. So the main frame was protected due to the plastic deformation and energy dissipation of BRBs, and beams and columns yielded and absorbed energy only in the subsequent larger displacement stage. 


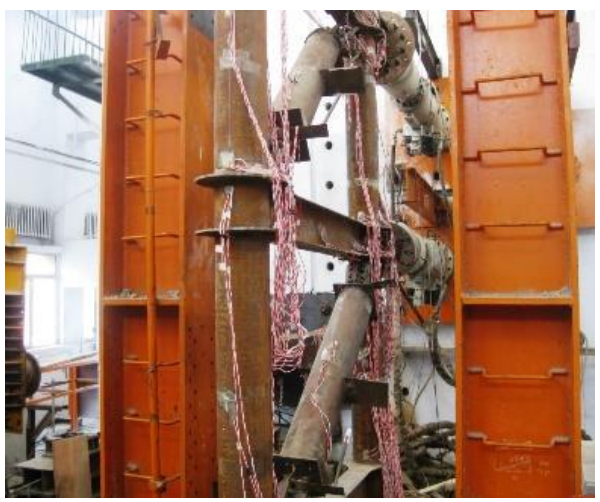

(a) Buckling of BRBs in two stories

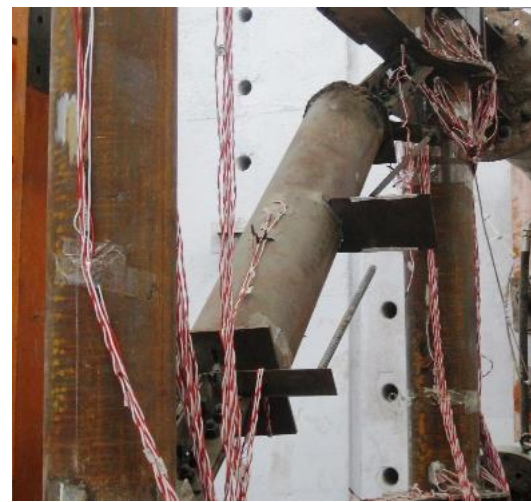

(b) Buckling of BRB

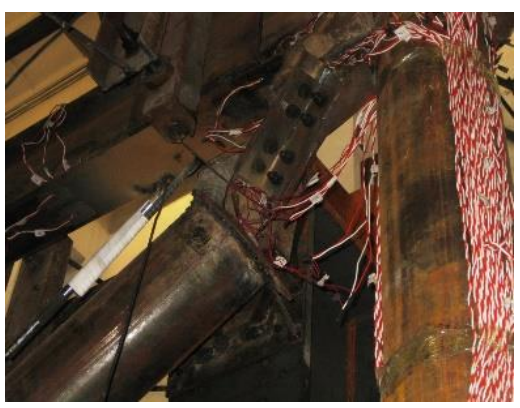

(c) Buckling of unrestrained connection

Fig. 8 Buckling of unrestrained connection segment of BRBs, (a), (b), (c) segment

After the test, BRBs were removed from the frame, steel tubes were stripped from BRBs. Due to the buckling and rotation of the unrestrained connection segments of BRBs, the concrete were crushed and cracked at the buckling position. As shown in Fig. 9, the length of restrained unyielding segment is not enough, the junction of restrained unyielding segment and restrained yielding segment became a central point of rotation, and the concrete suffered further crush due to the buckling of unrestrained connection segment.

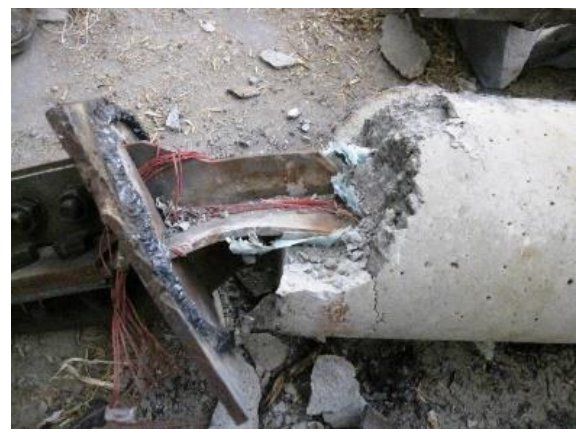

(a) Buckling of unrestrained connection segment and cracked concrete

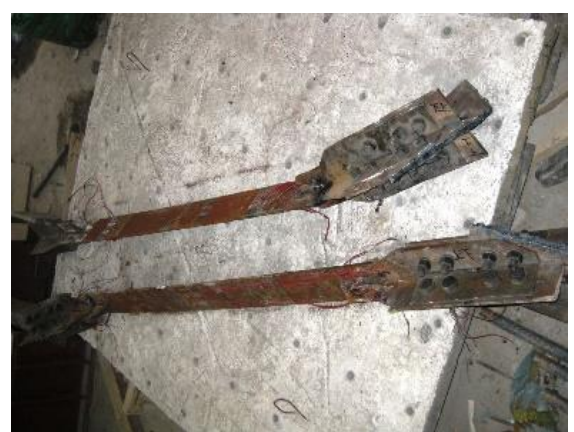

(b) Buckling of inner core of BRBs after disassemble

Fig. 9 Situations of concrete and inner cores of BRBs

Out-of-plane buckling may occur at the angle between the column and the beam during the beam-to-column joint "closes" due to frame sway, causing an out-of-plane moment on the BRB and the BRB connection. Although the system met the performance objectives for the design seismic demands, However, test also confirmed that the maximum ductility and cumulative plastic deformation (CPD) capacity of the BRBs adopted in the BRBCF was lower than that found in typical component test, and the drift levels achieved during the test were relatively small, albeit large enough to cause BRB yielding.

The large plastic deformation occurred at the inner core of $\mathrm{BRB}$, if the global stiffness of BRB is not large enough, BRB may buckle as a whole, or only buckle at the unrestrained connection segment due to relatively small stiffness compared to restrained segment. The root of unrestrained connection segment is a section of least area and least stiffness. Under axis compression and additive moment, if the stiffness of BRB connection joint is not enough, the outermost fiber of the root of unstrained segment yields firstly, and the unrestrained connection segment begins to buckle and rotates at the junction of unrestrained segment and restrained segment.

The performed test suggests that the reduction in the BRB maximum ductility and CPD capacities observed in this $1 / 3$ scale frame specimen could be due to the significant rotational demands imposed on the BRB unrestrained connection segments. The moment was amplified because the flexure of BRB end parts and became prominent especially for small flexural rigidity of BRB unrestrained connection segments. It shows that BRB end rotation subjected BRB unrestrained connection segments to large flexural moments, leading to premature yielding or even buckling tendency of BRB unrestrained connection segments. It is necessary to evaluate the stability of the BRB unrestrained connection segments as a separated segment. If the stability can't be satisfied, the stiffeners should be welded on the gusset plate edges in the direction perpendicular to the steel plate, and the cross section of unrestrained connection segment should be strengthened or connection collar can be added to BRB unrestrained connection segment for improving the load bearing and deformation capacity of gusset connections.

\section{Hysteretic curves and backbone curves}

The LVDT at top, middle and bottom beam indicated the displacements of specific location. The frame roof displacement, the second story and the first story displacement can be obtained via of the relationship of the displacements of different location, and the story drift can be calculated with the equation that the story displacement divided by the height of each story. The hysteretic curve of the base shear force versus the displacement of the roof is shown in Fig. 10. (a). Elastic behavior of specimen was displayed with a small hysteretic area in the first two cycles although there was some friction in the system. The story shear-displacement plots are presented in Fig. 10(c), (e), and Fig. 10(b), (d), (f) also presented the tri-linear backbone curves of overall structure and the separate stories within nearly $1 / 50$ drift. 


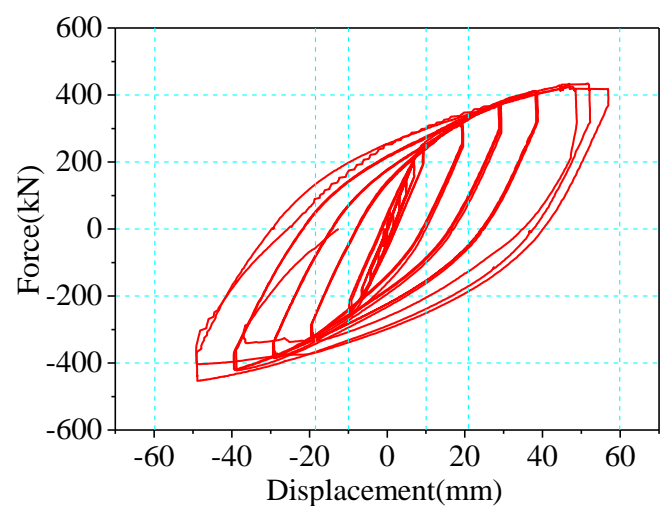

(a) Hysteretic curves of BRBCF

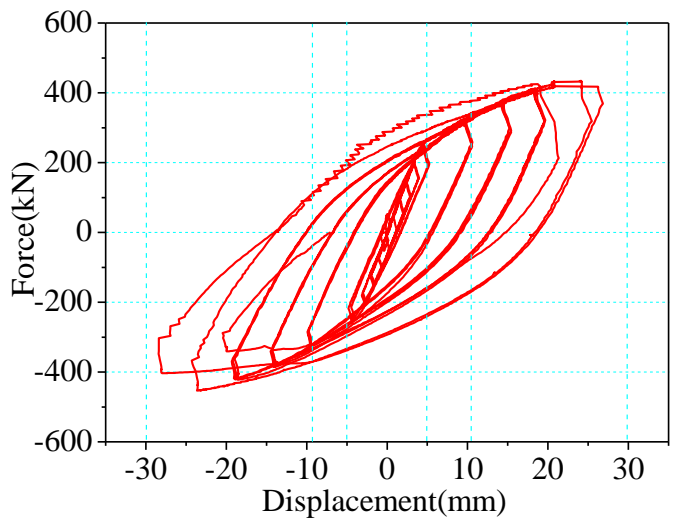

(c) Hysteretic curves of the first story

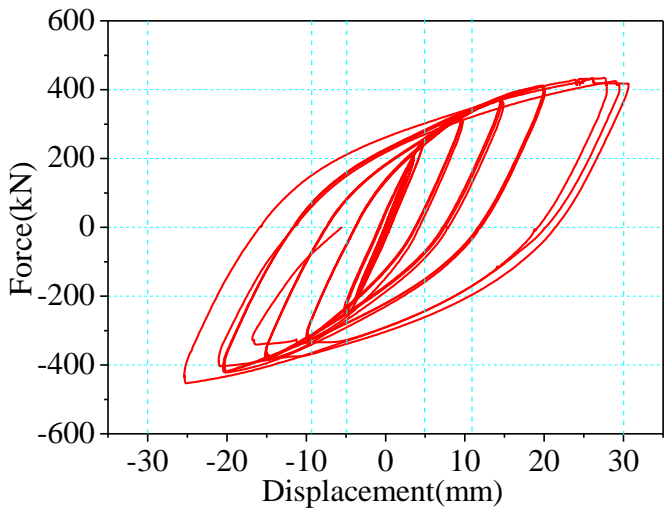

(e) Hysteretic curves of the second story

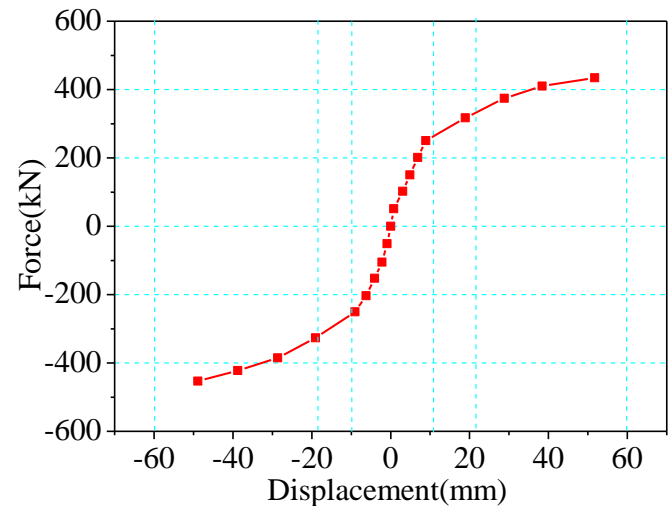

(b) Back-bone curve of BRBCF

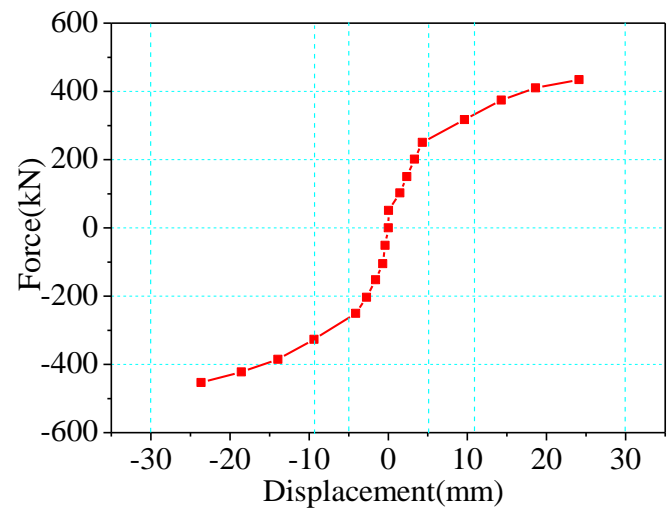

(d) Back-bone curve of the first story

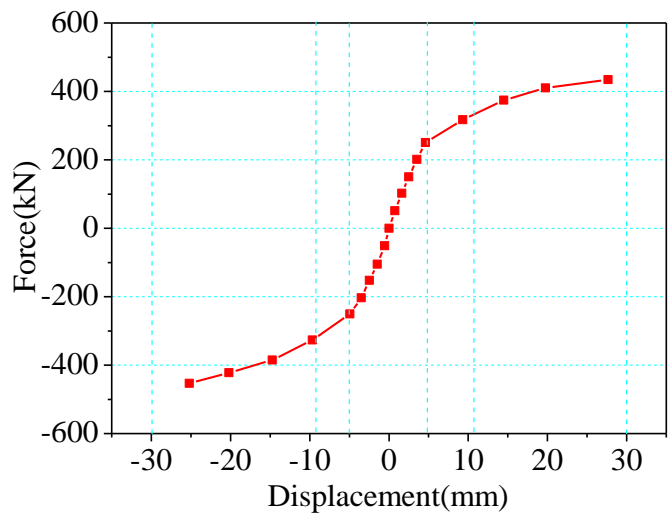

(f) Back-bone curve of the second story

Fig. 10 Force-Displacement hysteretic curves and back-bone curves

An electro-hydraulic servo actuator was attached to the reaction wall to apply an in-plane load to the specimen at the top story, so the lateral shear forces of two stories are the same as the applied actuator force. Two stories exhibited similar stiffness and sustained alike lateral shear force at the approximately same displacement amplitude. The BRBCF exhibited symmetrical mechanical behavior, except slightly larger stiffness and strength in compression stage relative to tension stiffness and strength, which was the result of the confinement effect of the lateral restraining mechanics to inner cores of BRBs and the friction between inner core and lateral restraining mechanics of BRBs. The positive and negative yielding displacements of BRBCF are $21.56 \mathrm{~mm}$ and $18.53 \mathrm{~mm}$, and the positive and negative yielding forces are $332 \mathrm{kN}$ and $323 \mathrm{kN}$. The maximum drift of BRBCF is close to $1 / 50$, ultimate positive and negative forces of BRBCF are $434 \mathrm{kN}$ and $453 \mathrm{kN}$. Although the buckling occurred on the BRB unrestrained connection segment, the stiffness of the BRBCF did not decrease significantly.

The energy dissipation coefficient $h_{e}$ can be calculated based on the hysteretic curves, which is equal to the sum of area $S_{\mathrm{ABC}}$ and $S_{\mathrm{CDA}}$ divided by the sum of area $S_{\mathrm{OBE}}$ and $S_{\mathrm{ODF}}$, and then divided by $2 \pi$, as shown in Fig. 11 and Equation 1.

$h_{e}=\frac{1}{2 \pi} \frac{S_{\mathrm{ABC}}+S_{\mathrm{CDA}}}{S_{\mathrm{OBE}}+S_{\mathrm{ODF}}}$

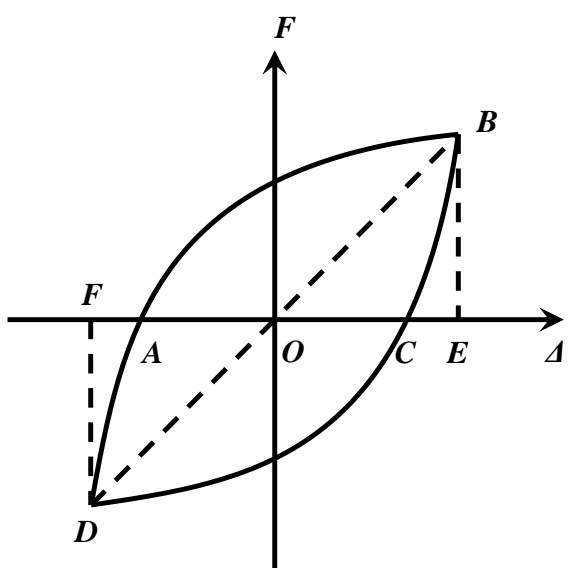

Fig. 11 Calculation of energy dissipation coefficient

Fig. 12 (a) shows the relationship of the area of hysteretic curves versus frame roof displacement, and Fig. 12 (b) showed the relationship between energy dissipation coefficient and frame roof displacement. The area of the 
hysteresis curve is the energy dissipated by the BRBCF, while the energy dissipation coefficient is used to evaluate the energy consumption capacity. As the plastic displacement of frame roof increases, structural energy dissipation

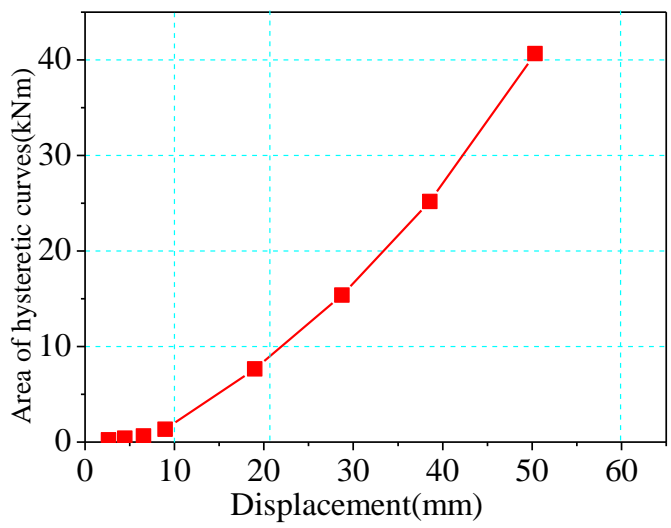

(a) The relationship of area of hysteretic curves and frame roof displacement capacity and energy dissipation coefficient increase, and the final energy dissipation coefficient reaches 0.885 , indicating that $\mathrm{BRBCF}$ has good hysteretic performance and energy dissipation capacity.

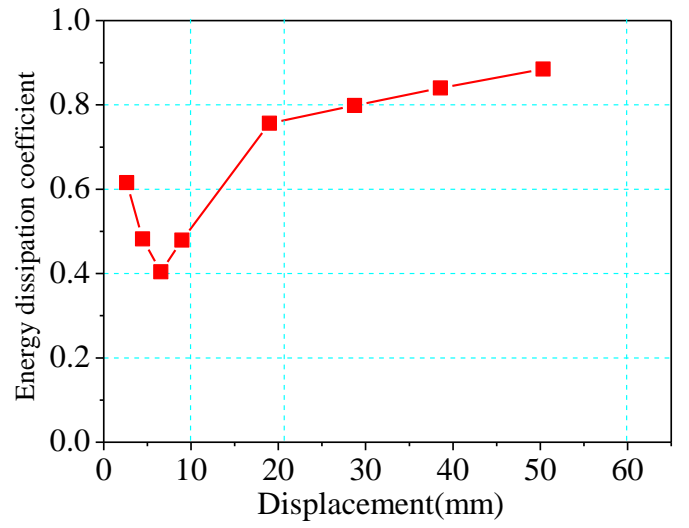

(b) The relationship of energy dissipation coefficient and frame roof displacement

Fig. 12 The energy dissipation capacity of BRBCF

\section{Comparison with experimental results of composite frame}

Comparative testing using the outer composite framework (CF) of BRBCF was conducted, and the components, joints and boundary conditions of both structures were the same. The hysteretic curve of the base shear force with the roof displacement of the CF frame and the corresponding backbone curve are shown in Fig. 13. When the displacement amplitude increased to $60 \mathrm{~mm}, \mathrm{CF}$ showed a decrease in strength and stiffness.

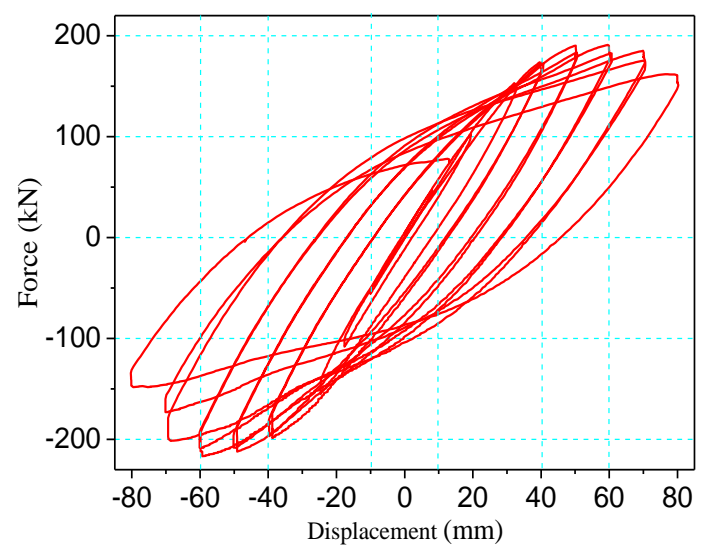

(a) Hysteretic curve

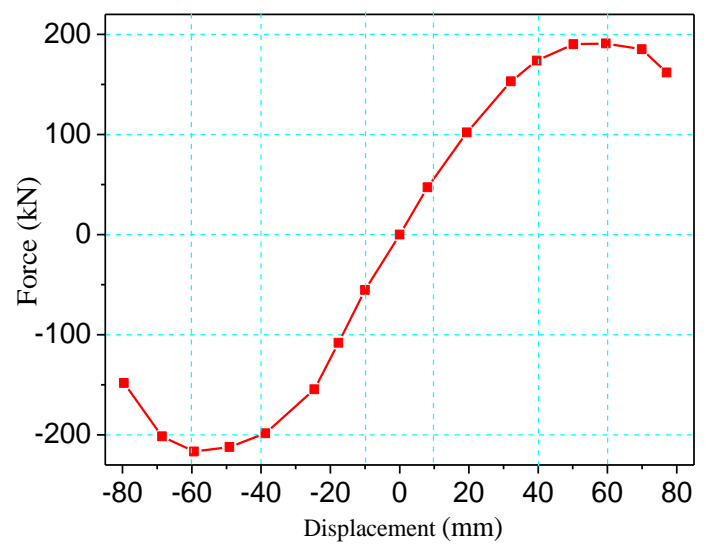

(b) Back-bone curve

Fig. 13 Hysteretic curves and back-bone curves of $\mathrm{CF}$

The backbone curves and tangent stiffness of BRBCF and CF were compared. Fig. 14 shows the backbone curves of two structures, which indicates the stiffness and load bearing capacity of BRBCF are larger than those of CF.
As shown in Fig. 15, BRBCF's tangent stiffness is 4.5 times of that of CF, and the stiffness of BRBCF after structural yielding is also larger than that of $\mathrm{CF}$ respectively. The curve shows that before the BRB buckling, the stiffness of the BRBCF did not decrease during the plastic development of the components. CF showed a decrease in strength and stiffness when displacement amplitude increased to $60 \mathrm{~mm}$, which also indicated good ductility of CF. With the help of $\mathrm{BRB}$, the lateral bearing capacity and stiffness of the CF have been significantly improved.

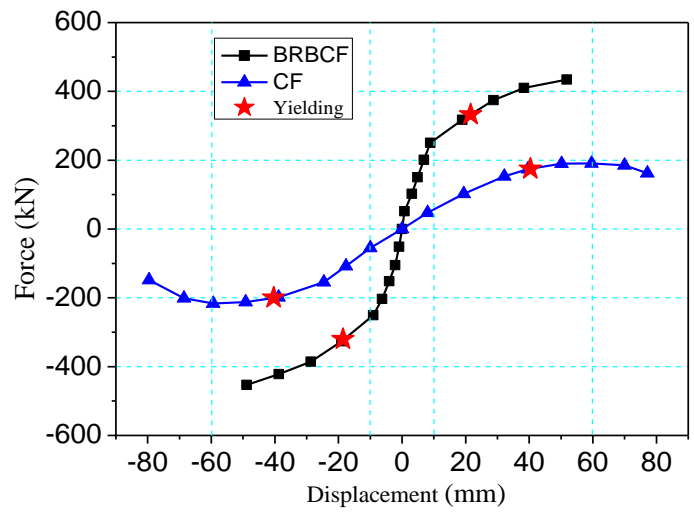

Fig. 14 Comparison of backbone curves

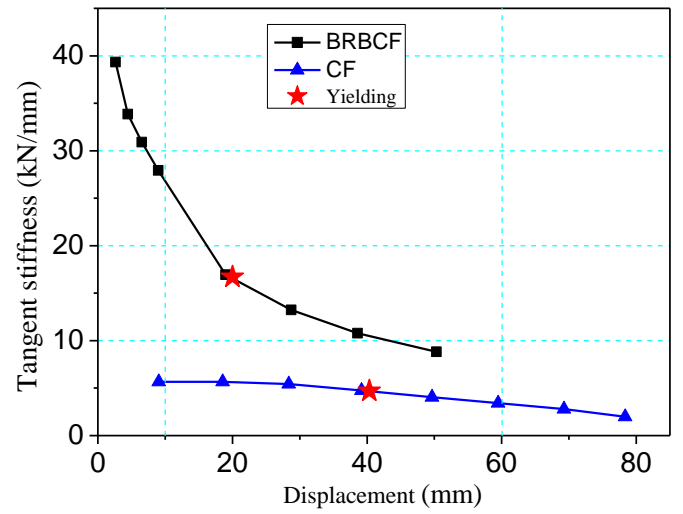

Fig. 15 Comparison of secant stiffness

When the lateral stiffness is insufficient to comply with the code drift requirements imposed for moment resisting frame systems in earthquake-prone regions, the frame can be retrofitted with BRBs for larger structural stiffness and smaller structural displacement. Although it could also be noted that the seismic 
demand of BFBCF is also greater than CF due to the larger lateral stiffness of structures, and the larger load bearing capacity should be required for BRBCF to resist the horizontal force and control the lateral displacement. The large lateral stiffness and load bearing capacity of BRBCF will also result in the bigger and fuller hysteretic loops, BRBs are usually used as energy dissipation components in structural system, so the CF retrofitted with BRBs can dissipate more energy and mitigate the damage of main structural components.

As shown in Table 2, the loads of BRBCF at maximum negative and positive displacement are 1.40 times and 1.31 times of yielding load, and the loads of $\mathrm{CF}$ at maximum negative and positive displacement are 1.08 times and 1.09 times of yielding load. The ratios of negative and positive yielding load $V$ of $\mathrm{BRBCF}$ and $\mathrm{CF}$ are 1.61 and 1.90; the ratios of negative and positive maximum load $V_{\max }$ of BRBCF and $\mathrm{CF}$ are 2.09 and 2.27; the ratios of negative and positive ultimate load $V_{u}$ of BRBCF and $\mathrm{CF}$ are 3.06 and 2.68. When the CF frame is equipped with BRBs, the stiffness and load bearing capacity are significantly improved.

Table 2

Comparison of load bearing capacity of BRBCF and CF

\begin{tabular}{|c|c|c|c|c|c|c|c|c|}
\hline \multirow{2}{*}{ Specimens } & \multirow{2}{*}{$\begin{array}{c}\text { Load } \\
\text { Direction }\end{array}$} & \multicolumn{2}{|c|}{$\begin{array}{l}\text { Yielding load and } \\
\text { dispalcement }\end{array}$} & \multicolumn{2}{|c|}{$\begin{array}{l}\text { Maximum load and } \\
\text { dispalcement }\end{array}$} & \multicolumn{2}{|c|}{$\begin{array}{l}\text { Ultimate displacement } \\
\text { and corresponding load }\end{array}$} & \multirow{2}{*}{$V_{\max } / V_{y}$} \\
\hline & & $\begin{array}{r}V_{y} \\
(\mathrm{kN})\end{array}$ & $\begin{array}{c}\Delta_{y} \\
(\mathrm{~mm}) \\
\end{array}$ & $\begin{array}{r}V_{\max } \\
(\mathrm{kN}) \\
\end{array}$ & $\begin{array}{c}\Delta_{\max } \\
(\mathrm{mm}) \\
\end{array}$ & $\begin{array}{r}V_{u} \\
(\mathrm{kN}) \\
\end{array}$ & $\begin{array}{c}\Delta_{u} \\
(\mathrm{~mm})\end{array}$ & \\
\hline \multirow{2}{*}{ BRBCF } & Positive & 332.17 & 21.56 & 434.04 & 51.77 & 434.04 & 51.77 & 1.31 \\
\hline & Negative & -322.84 & -18.53 & -453.39 & -48.87 & -453.39 & -48.87 & 1.40 \\
\hline \multirow{2}{*}{$\mathrm{CF}$} & Positive & 175.02 & 40.37 & 190.97 & 59.58 & 161.87 & 77.13 & 1.09 \\
\hline & Negative & -200.46 & -40.35 & -216.67 & -59.38 & -148.07 & -79.59 & 1.08 \\
\hline \multirow{2}{*}{ Ratio } & Positive & 1.90 & 0.53 & 2.27 & 0.87 & 2.68 & 0.67 & \\
\hline & Negative & 1.61 & 0.46 & 2.09 & 0.82 & 3.06 & 0.61 & \\
\hline
\end{tabular}

The hysteresis loops of the displacement amplitude of 50mm of BRBCF and $\mathrm{CF}$ are selected and compared, as shown in Fig. 16 (a), the hysteretic loop of BRBCF is much bigger than that of CF. The area of hysteretic curves and energy dissipation coefficient of BRBCF are compared to those of CF as shown in Fig. 16 (b) and Fig. 16 (c).

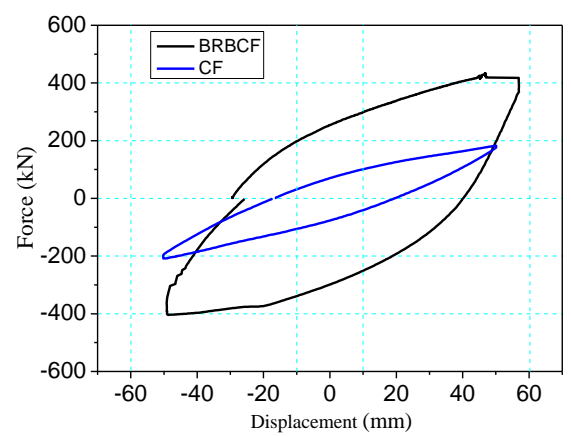

(a) Hysteretic loops of BRBCF and $\mathrm{CF}$ at the roof displacement of $50 \mathrm{~mm}$

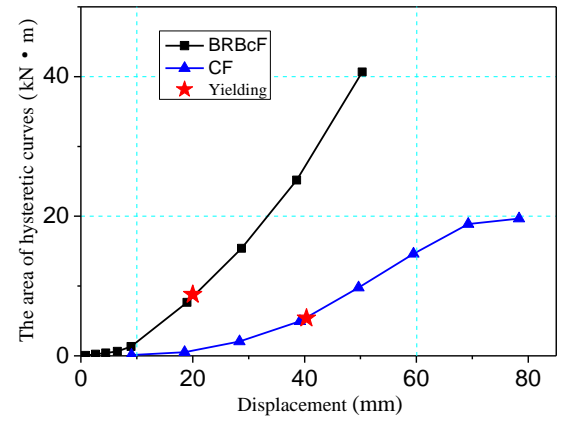

(b) The area of total hysteretic curves

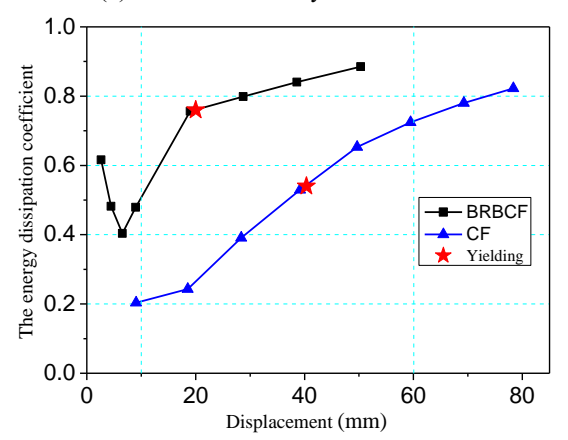

(c) The energy dissipation coefficients

Fig. 16 Comparison of energy dissipation capacity of $\mathrm{BRBCF}$ and $\mathrm{CF}$
Total hysteresis loops area of BRBCF is $40.65 \mathrm{kN} \cdot \mathrm{m}$ that is 2.15 times of that of CF of $18.88 \mathrm{kN} \cdot \mathrm{m}$ at the frame roof displacement of $50 \mathrm{~mm}$. The energy dissipation coefficient of BRBCF is 0.89 that is 1.14 times of that of CF of 0.78 at the frame roof displacement of $50 \mathrm{~mm}$, and the ratio is 2.68 at the frame roof displacement of $20 \mathrm{~mm}$. BRBs play the important role of improving the structural system's energy dissipation capacity.

\section{Summary and conclusions}

The buckling-restrained braced composite frame (BRBCF) system was researched in this paper, which consisted of concrete-filled circular hollow section (CHS) steel columns, steel beams, and BRBs. The quasi-static cyclic test of one 1/3 scale 1-bay 2-story BRBCF was conducted, which was compared with the same outer composite frame. After installed with the BRBs, the lateral stiffness, ultimate load bearing capacity and energy dissipation capability of the composite frame were improved evidently. Under the significant drift requirements of the subsequent quasi-static cycle test, BRBCF showed excellent performance without strength or stiffness degradation, and had good ductility and energy dissipation capacity.

The ratios of yield load, maximum load and ultimate load of BRBCF to CF at positive displacement are 1.9, 2.27 and 2.68, respectively, and they are 1.61, 2.09 and 3.06 at negative displacement, respectively. The stiffness of BRBCF before and after yielding are 4.5 and 2.5 times of those of $\mathrm{CF}$, respectively. The maximum hysteresis loop area of BRBCF is 2.15 times of that of CF. The energy dissipation coefficient of $\mathrm{BRBCF}$ is 2.68 times of that of $\mathrm{CF}$ when the frame roof displacement is $20 \mathrm{~mm}$, and 1.14 times of that of $\mathrm{CF}$ when the frame roof displacement is $50 \mathrm{~mm}$. The stiffness of unrestrained connection segment of BRBs is very important, under axis compression and additive moment, the unstrained segments buckled and rotated at the junction of unrestrained segment and restrained segment.

According to Chinese code, the frame system met the performance objectives for the design seismic demands. The better performance should be achieved on condition that the stability performance of BRB joint was ensured. The test suggests that the reduction in the BRB maximum ductility and energy dissipation capacity observed in this $1 / 3$ scale frame specimen compared to typical BRB component tests could be due to the significant flexural demands imposed on the BRB unrestrained connection segments. It is necessary to evaluate the stability design of the BRB joints and consider the effects of the added stiffeners or connection collar in improving the load bearing and deformation capacity of gusset connections.

\section{Acknowledgements}

The support of Scientific Research Fund of Institute of Engineering Mechanics, China Earthquake Administration (Grant No. 2018D04), National Science Foundation of China through projects (Grant No. 51978220). All the opinions, findings, and conclusions or recommendations expressed in this material are those of the authors and do not necessarily reflect those of the Foundations. 


\section{References}

[1] Aiken I. D., Mahin S. A. and Uriz P., "Large-scale testing of buckling restrained braced frames", Japan Passive Control Symposium, Tokyo Institute of Technology, Yokohama, Japan, 2002.

[2] Iwata M., Kato T. and Wada A., "Buckling-restrained braces as hysteretic dampers", Behavior of Steel Structures in Seismic Areas, 33-38, 2000.

[3] Iwata M., Kato T. and Wada A., "Performance evaluation of buckling-restrained braces in damage- controlled structures", STESSA 2003-Behaviour of Steel Structures in Seismic Areas. Routledge, 37-43, 2003.

[4] Tsai K. C., Hsiao P. C., et al., "Pseudo-dynamic test of a full-scale CFT/BRB frame-part ii: seismic performance of buckling-restrained braces and connections", Earthquake Engineering and Structural Dynamics, 37, 1099-1115, 2008.

[5] Christopulos A. S., "Improved seismic performance of BRBFs", M.S. thesis of University of Washington, Seattle, USA, 2005.

[6] Roeder C. W., Lehman D. E. and Christopulos A, "Seismic performance of special concentrically braced frames with buckling restrained braces", 8th U.S. National Conference on Earthquake Engineering, Earthquake Engineering Research Institute, Oakland, California, USA, Paper No. 1503, 2006

[7] Chou C. C., Liou G. S. and Yu J. C., "Compressive behavior of dual-gusset-plate connections for buckling- restrained braced frames", Journal of Constructional Steel Research, 76, 54-67, 2012

[8] Chou C. C., Liu J. H. and Pham D. H., "Steel buckling-restrained braced frames with single and dual corner gusset connections: seismic tests and analyses", Earthquake Engineering and Structural Dynamics, 41, 1137-1156, 2012.

[9] Tsuyoshi H., Taichiro O., Kouichi K. and Masayoshi N., "Out-of-plane stability of bucklingrestrained braces", ASCE Structures Congress, Orlando, Florida, USA, 939-949, 2010.

[10] Chuang M. C., Tsai, K. C. et al, "Critical limit states in seismic buckling-restrained brace and connection designs”, Earthquake Engineering and Structural Dynamics, 44, 1559-1579, 2015.
[11] Zhao J. X., Lin F. X. and Wang Z., "Effect of non-moment braced frame seismic deformations on buckling-restrained brace end connection behavior: Theoretical analysis an subassemblage tests", Earthquake engineering and structural dynamics, 45, 359-381, 2016.

[12] Zhao J. X., Chen R. B., Wang Z. and Pan Y. "Sliding corner gusset connections for improved buckling-restrained braced steel frame seismic performance: Subassemblage tests", Engineering Structures, 172, 644-662, 2018

[13] Zhao J. X., Lin F. X. and Wang Z., "Seismic design of buckling-restrained brace welded end connection considering frame action effects: Theoretical, numerical and practical approaches", Engineering Structures, 132, 761-777, 2017.

[14] Jamkhaneh M. E., Ebrahimi A. H. and Amiri M. S., "Seismic Performance of Steel-Braced Frames with an All-Steel Buckling Restrained Brace", Practice periodical on structural design and construction, 23, 3, 04018016.1-16, 2018.

[15] Sadeghi S. and Rofooei F. R., "Improving the seismic performance of diagrid structures using buckling restrained braces" Journal of Constructional Steel Research, 166, 105905, 2020

[16] National Standard of the People's Republic of China, "Code for seismic design of buildings. National Standards of the People's Republic of China (GB50011-2010)" China Architecture $\&$ Building Press, Beijing, China, 2010. (in Chinese)

[17] Industrial Standard of the People's Republic of China, "Code for design of steel-concrete composite structure (DL/T5085-1999)”, China Electric Power Press, Beijing, China, 1999. (in Chinese)

[18] National Standard of the People's Republic of China, "Code for design of steel structure (GB50017-2003)", China Planning Press, Beijing, China, 2003. (in Chinese)

[19] Cameron J. B., et al. "Component Testing, Seismic Evaluation and Characterization of Buckling- Restrained Braces", Journal of structural engineering (ASCE), 130, 6, 880-894, 2004.

[20] Industrial Standards of the People's Republic of China, "Specification of testing methods for earthquake resistant building (JGJ 101-2015)", China Architecture \& Building Press, Beijing, China, 2015. (in Chinese) 